\title{
EL TRASFONDO JURÍDICO Y RETÓRICO de la "Pro Caelio" de Cicerón*
}

\author{
[Legal and Rhetoric background of Cicero's "Pro Caelio"]
}

\author{
TAMÁS NÓTÁRI** \\ Károli Gáspár University, Budapest, Hungría
}

\begin{abstract}
RESUMEN
La oración Pro Caelio de Cicerón, pronunciada en el 56 a. C., representa un paso importante en la lucha de Cicerón en contra de Clodio (y su grupo). La primera etapa de la relación hostil puede datarse en el 73, cuando Clodio acusó de incestum a la media hermana de Terencia, mujer de Cicerón. Éste quiso vengar la afrenta en el año 61, cuando dio testimonio en contra de Clodio en el juicio de la Bona Dea. Clodio respondió requiriendo la expulsión de Cicerón en el 58 y la destrucción de su casa en el Palatino. En el 56, de resultas de una peculiar coincidencia de relaciones
\end{abstract}

\begin{abstract}
Cicero's Pro Caelio Oratio, delivered in 56 b. C., represents an important step in Cicero's fight against Clodio (and his group). The first stage of the hostile relationship dates back to 73, when Clodio accused the half-sister of Terentia, Cicero's wife, of incestum. In 61, he sought revenge and testified against Clodio at the Bona Dea trial. Clodio answered back in 58 and requested Cicero's expulsion and destroyed Cicero's house in the Palatine. In 56, as a result of a peculiar coincidence of political and private relationships, Cicero had the chance to severely hit Clodia, Clodio's
\end{abstract}

ReCiBIDO el 2 de julio y ACEPTADO el 24 de agosto de 2013

* Traducido por Carlos Felipe Amunátegui Perelló, profesor de Derecho romano, de la Pontificia Universidad Católica de Chile.

** Dr. habil., PhD. Senior Research Fellow Institute for Legal Studies of the Center for Social Sciences of the Hungarian Academy of Sciences, Associate Professor of Roman Law, Károli Gáspár University, Faculty of Law, H-1042 Budapest, Viola u. 2-4. E-mail: tamasnotari@yahoo.de 
políticas y privadas, Cicerón tuvo la oportunidad de golpear duramente a Clodia, la hermana mayor de Clodio, con su Pro Caelio, burlándose de ella en el juicio con un humor homicida, utilizando una parodia con el teatro romano, especialmente con la comedia.

Palabras clave

Cicerón - Retórica clásica-Lex Plautia de vi-Pro Caelio - Ludi Megalenses. elder sister, with is Pro Caelio, by means of humorous invective at her expense at the trial, using a parody with the Roman theater, specially, the comedy.

\section{KEYWORDS}

Cicero - Classic rhetoric - Lex Plautia de vi-Pro Caelio - Ludi Megalenses.

\section{AnTECEDENTES DE LA DEMANDA}

En abril del año 56 a.C. M. Celio, de entonces 25 años $^{1}$, fue acusado por la quaestio de vi con L. Sempronio Atratino como principal prosecutor y L. Herenio Balbo y P. Clodio como subscriptores. El acusado hizo la declaración de defensa. Luego habló M. Licinio Craso y-ubicándose al final de la lista, según su costumbre ${ }^{2}-$ Cicerón actuó como consejero de la defesa. La acusación fue hecha probablemente en base a la lex Plautia de vi $(65 / 4)^{3}$, la cual había sido redactada, según el relato de Cicerón, para reprimir los hechos de ciudadanos infames que llevaban adelante revueltas, atacando el Senado con armas, utilizando la violencia en contra de los magistrados y atentando en contra del Estado ${ }^{4}$. En cuanto a los actos por los que Celio fue acusado, los primeros tres fueron expuestos con mayor detalle en las declaraciones de defensa hechas por Celio y Craso, y de ellos sólo sabemos por el resumen de los mismos hecho por Cicerón ${ }^{5}$.

Cicerón se reservó para sí la refutación del cargo de asesinato en contra del filósofo alejandrino Dión ${ }^{6}$. Los cargos de la acusación están conectados en alguna forma con los legados de Alejandría, que querían protestar ante el Senado en contra de la reposición en el trono egipcio de Tolomeo XII por parte de Roma (lo que puede establecerse a primera vista que concierne a los cargos segundo y cuarto de

${ }^{1}$ Cf. Plinius, Naturalis historia 7,165; HeInze, Richard, Ciceros Rede pro Caelio, en Hermes, Zeitschrift für klassische Philologie, 60 (Berlin, 1925), p. 194; STROH, Wilfried, "Taxis" und Taktik. Die advokatische Dispositionskunst in Ciceros Gerichtsreden (Stuttgart, Teubner, 1975), p. 243.

${ }^{2}$ Cicero, Brutus 190; Orator 130; Quintilianus, Institutio oratoria 4,2,27.

${ }^{3}$ Acerca de la lex Plautia, véase: Costa, Emilio, Cicerone giureconsulto (Bologna, Nicola Zanichelli, 1927), II, p. 91; KUNKEL, Wolfgang, Untersuchungen zur Entwicklung des römischen Kriminalverfahrens in vorsullanischer Zeit (München, Beck, 1962), p. 123; MüNZER, Friedrich, Römische Adelsparteien und Adelsfamilien (Stuttgart, Metzler, 1920), p. 200; CLASSEN, Johannes, Ciceros Rede für Caelius, en Temporini, Hildegard - HaAse, Wolfgang (editores), Aufstieg und Niedergang der römischen Welt (Berlin - New York, De Gruyter, 1973), I,3, p. 63; MoMMSEN, Theodor, Römisches Strafrecht (Leipzig, Duncker \& Humbolt, 1899), p. 564.

${ }^{4}$ Cicero, Pro Caelio 1.

${ }^{5}$ Ibíd., 23: "Itaque illam partem causae facile patior graviter et ornate a M. Crasso peroratam de seditionibus Neapolitanis, de Alexandrinorum pulsatione Puteolana, de bonis Pallae".

${ }^{6}$ Ibíd., 23,51-55. 
la acusación). Los legados, liderados por Dión, llegaron a Roma en el 57, pero el rey Tolomeo, respaldado por Pompeyo, hicieron los mayores esfuerzos para frustrar la audiencia ante el Senado ${ }^{7}$. La acusación señalaba que Celio había estado involucrado en estos actos de Tolomeo y Pompeyo desde el principio. La pulsatio Puteolana fue probablemente un ataque hecho en contra de los legados de Alejandría inmediatamente después de su llegada a Puteoli. No puede ser descartado que las seditiones Neapolitanae estén conectadas con estos eventos de una manera u otra. Si los legados que se dirigían a Roma desde Nápoles por la vía Appia se sirvieron de la protección de un magistrado, entonces puede llamársela seditio, usando el término técnico romano, puesto que denota un desafío en contra del poder del Estado ${ }^{8}$. No podemos ni probar ni descartar la relación entre los bona Pallae con los legados de Alejandría 9 . A este respecto, es necesario referirse a la visión que señala que la demanda en cuestión puede ser considerada una disputa jurídica de naturaleza primariamente política. En este sentido, se buscaba atacara Pompeyo, el protector (patronus) de Tolomeo, y la misión de Cicerón era privar al caso de cualquier implicancia en la política contingente. En contra de este punto de vista, pueden señalarse los siguientes aspectos: los prosecutores estaban básicamente motivados por motivos privados antes que políticos ${ }^{10}$.

En particular, el hecho que en febrero del 56 Celio acusase de ambitus L. Calpurnio Bestia ${ }^{11}$, padre natural de L. Sempronio Atratino, entonces de diecisiete años de edad, quien fue absuelto del cargo de soborno fue defendido por Cicerón; así, éste quería emplazarlo en una segunda oportunidad en razón del delito de ambitus ${ }^{12}$. Esta segunda acusación fue evitada por Atratino acusándolo a él con el delito de vis. En consecuencia, en opinión de Heinze, las consideraciones políticas en esta acusación habrían constituido un medio, más que su objetivo $^{13}$. La Popularidad de Pompeyo estaba en sus mínimos ${ }^{14}$, por lo que para los acusantes era incluso ventajoso el poder atacar a Celio en cuanto partidario de Pompeyo. A estos efectos, Cicerón mismo intentó mitigar el lado político de la controversia (de hecho ni siquiera se menciona el nombre de Pompeyo en todo el Pro Caelio) ${ }^{15}$. Además de los cargos específicos de la acusación, Cicerón trata tocar varias materias que en verdad no están comprendidas en los cargos, en especial el supuesto intento de Celio de asesinar a Clodia, la viuda de Metello Celer $^{16}$. El trata el intento de envenenar a Clodia de manera separada, pero, por

${ }^{7}$ Véase: Dio Cassius, Historia Romana 39,13; Cicero, De haruspicum responso 34; STRABo, Geographica 17,7,96.

${ }^{8}$ Mommsen, Theodor, cit. (n. 3), p. 532.

${ }^{9} \mathrm{~S}$ TroH, Wilfried, cit. (n. 1), p. 245.

${ }^{10}$ Cf. Cicero, Pro Caelio 56.

${ }^{11}$ Acerca del personaje, véase: MünZER, Friedrich, Aus dem Leben des M. Caelius Rufus, en Hermes. Zeitschrift fiur klassische Philologie, 44 (Berlin, 1909), pp. 135.

${ }^{12}$ Cicero, Pro Caelio 16,56,78.

${ }^{13}$ Heinze, Richard, cit. (n. 1), p. 197; ClasSEN, Johannes, cit. (n. 3), p. 93.

${ }^{14}$ Cf. Cicero, Pro Caelio 78; Epistulae ad Quintum fratrem 2,6,6.

${ }^{15}$ STROH, Wilfried, cit. (n. 1), p. 246.

${ }^{16}$ Costa, Emilio, cit. (n. 3), II. p. 93. 
una aseveración realizada ${ }^{17}$ parece claro que este elemento juega un rol central en la cadena de demostraciones de la evidencia. En consecuencia, Celio habría obtenido dinero de Clodia para poder contratar a los asesinos de Dión ${ }^{18} \mathrm{y}$, más tarde, el habría querido envenenar a Clodia -de quien el dinero provendría- para deshacerse de la mujer de quien provendría el dinero y que sólo después habría sido consciente del asesinato ${ }^{19}$.

\section{El caso de la "Bona DeA"}

El desarrollo de una relación hostil entre Cicerón y P. Clodio, como también respecto a su hermana Clodia, no puede comprenderse sin tener presente el testimonio entregado por Cicerón en el llamado juicio de la Bona Dea y de las causas que lo llevaron a hacerlo. Fue a comienzos de diciembre del año 62 cuando las más conspicuas mujeres de Roma, incluidas las virgines Vestales, celebraron el festival de la Bona Dea en la casa del pontifex maximus, César. El nombre de Bona Dea es la transliteración directa del griego Agathē Theos, una deidad que llegó a ser generalmente conocida como una diosa de la sanación ${ }^{20}$. De conformidad a las inscripciones que se refieren a ella y a las representaciones encontradas en Attica, se trata de una representación de la figura de Hygeia ${ }^{21}$. Este ritual se realizaba en Roma en la casa de un magistratus cum imperio y sólo las matronae de la élite y las sacerdotisas de Vesta podían participar de él ${ }^{22}$. La festividad era dirigida por la mujer del magistratus, por lo que la Bona Dea no tenía un sacerdocio propio ${ }^{23}$. En cuanto al presente caso, es importante señalar que todo macho, fuese animal o humano, estaba absolutamente excluido del ritual. Las fuentes históricas no nos permiten establecer un cuadro exacto de lo sucedido ${ }^{24}$. No obstante, podemos dar por cierto, con una aceptable seguridad, los siguientes hechos: de alguna manera, Clodio se introdujo en la casa (Plutarco afirma que encontró la puerta abierta y simplemente entró). Se habría disfrazado de citarista ${ }^{25}$, pero la afirmación hecha por Plutarco y Apiano de que el disfrazarse de mujer habría sido sencillo para él, puesto que todavía no tenía edad de afeitarse es obviamente errada, pues olvidan que para entonces Clodio tenía veintinueve años. Dión Casio afirma que su propósito era seducir a la mujer de César, Pompeya (lo cual, según el mismo Dión Casio sí habría conseguido), aunque no puede haber certeza de esto. En cualquier

${ }^{17}$ Cicero, Pro Caelio 56.

${ }^{18}$ Ibíd., 52.

${ }^{19}$ STrOH, Wilfried, cit. (n. 1), p. 249.

${ }^{20}$ Macrobius, Saturanalia 1,12,25.

${ }^{21}$ LatTe, Kurt, Römische Religionsgeschichte (München, Beck, 1967), p. 228.

${ }^{22}$ Cicero, Epistulae ad Atticum 1,13,3; De haruspicum responso 37; Plutarchus, Cicero 19;

Dio Cassius, Historia Romana 37,35,4; 37,45,1.

${ }^{23}$ Latte, Kurt, cit. (n. 21), p. 230.

${ }^{24}$ Plutarchus, Cicero 28; Caesar 9; Suetonius, Divus Iulius 6,2; Appianus, Bella civilia 2,14,52; Dio Cassius, Historia Romana 37,45; Livius, Ab Urbe condita, Periochae 103.

${ }^{25}$ Cicero, De haruspicum responso 44; Plutarchus, Cicero 28,2; Caesar 10,1; Iuvenalis, Saturae 6,337. 
caso, el ritual fue dirigido por la madre de César, Aurelia, y no por Pompeya ${ }^{26}$. La festividad interrumpida fue, más tarde, repetida por las sacerdotisas de Vesta (instauratio) ${ }^{27}$.

En el Senado, el escándalo de la Bona Dea fue planteado primeramente por Q. Cornificio, ante lo cual el Senado lo remitió a las sacerdotisas de Vesta y a los pontífices, quienes sesionaron bajo la presidencia del pontifex maximus, César ${ }^{28}$. Además de César, este cuerpo incluía a otro miembro que participó más tarde en el juicio: L. Cornelio Léntulo Níger, quien era flamen Martialis ${ }^{29}$. El Senado recibió un informe que establecía que las perturbaciones del ritual de la Bona Dea eran nefas. Luego de este informe, aunque antes del juicio, César se divorció de su esposa y anunció que él no comparecería voluntariamente en juicio como testigo, confirmando, así, a Clodio que no habría habido ningún quiebre en su amistad ${ }^{30}$. El Senado aceptó el informe y resolvió establecer una jurisdicción especial a fin de investigar el incestum cometido por Clodio ${ }^{31}$. Los miembros del tribunal no fueron elegidos del album iudicum por suertes -según era costumbre en las quaestiones-, sino que el pretor seleccionó a personas específicas, lo cual levantó la sospecha de que los jueces estaban predispuestos en contra de Clodio desde el comienzo ${ }^{32}$. Por esta razón, Fufio Caleno, tribunus plebis, vetó la acusación remitida por M. Pisón $^{33}$. La cuestión fue derivada al pueblo, de entre quienes, tres adversarios de Clodio -Catón, Favonio y Hortensio- actuaron resueltamente. Entonces, el Senado fue convocado nuevamente y, una vez superada la resistencia de Fufio Caleno, decidieron proceder de la forma originalmente planeada -acerca de este hecho Cicerón informó a Ático el 13 de febrero ${ }^{34}$. En la sesión siguiente del Senado Fufio hizo dos propuestas: en primer término, aceptando que el juicio de Clodio debía ser llevado adelante; en segundo término, señalando que los jueces debía ser sorteados ${ }^{35}$. La primera propuesta fue aceptada, mientras que la segunda fue desechada ${ }^{36}$, encomendando el Senado a Fufio que llevase el juicio ante el pueblo. Cicerón alega que esto ocurrió así, porque Hortensio y su círculo estaban convencidos de que Clodio habría sido condenado por cualquier tribunal ${ }^{37}$. De esta manera, la acusación formal fue hecha antes del 15 de marzo del 61. Acerca de la

${ }^{26}$ Suetonius, Divus Iulius 74,2.

${ }^{27}$ Cicero, Epistulae ad Atticum 1,13,3.

${ }^{28}$ Cicero, Epistulae ad Atticum 1,13,13; Macrobius, Saturnalia 3,13,11.

${ }^{29}$ Balsdon, John Percy Vyvian Darcre, Fabula Clodiana, en Historia, Zeitschrift für alte Geschichte, 15 (Stuttgart, 1966), p. 67.

${ }^{30}$ Cicero, Epistulae ad Atticum 1,13,3; Plutarchus, Caesar 10,8-10; Suetonius, Divus Iulius 6,2,74,2; ApPIANus, Bella civilia 2,14,52; Dio Cassius, Historia Romana 37,45.

${ }^{31}$ Cicero, Epistulae ad Atticum 1,13,3.

${ }^{32}$ Balsdon, John Percy Vyvian Darcre, cit. (n. 29), p. 69.

${ }^{33}$ Cicero, Paradoxa Stoicorum 4,32.

${ }^{34}$ Cicero, Epistulae ad Atticum 1,14,5.

${ }^{35}$ Tatum, W. Jeffrey, Cicero and the Bona Dea Scandal, en Classical Philology, 85 (Chicago, 1990), p. 206.

${ }^{36}$ Balsdon, John Percy Vyvian Darcre, cit. (n. 29), p. 70.

${ }^{37}$ Cicero, Epistulae ad Atticum 1,16; 2,4-5; Spielvogel, Jörg, Clodius P. Pulcher, eine politische Ausnahmeerscheinung der späten Republik? en Hermes. Zeitschrift für klassische Philologie, 125. (Stuttgart, 1997), p. 60. 
demanda misma, conocemos más bien pocos datos. La acusación fue presentada por tres personas, tres Cornelios Léntulos: L. Cornelio Léntulo Crus, L. Léntulus Cornelio Léntulo Niger (flamen Martialis) y Cn. Cornelio Marcellino ${ }^{38}$.

En contra de la acusación, Clodio intentó una coartada y demostrar que el día del ritual de la Bona Dea él había estado en Interamna y no en Roma. Para refutar esta coartada, muchas matronae que participaron en el ritual de la Bona Dea testificaron, incluyendo a la madre de César, Aurelia, y a la hermana mayor de César, Iulia. De la misma manera, Cicerón testificó que en el día del ritual Clodio lo visitó en Roma -algunas fuentes ${ }^{39}$ aseguran que esta visita fue hecha tres horas antes del escándalo (tarde en la noche), mientras que otras interpretaciones ${ }^{40}$ aseguran que habría tenido lugar durante la salutatio, en la mañana. Eventualmente, Clodio fue absuelto. Muchas causas explican tal resultado de la demanda: no puede descartarse que los miembros del tribunal hayan sido sobornados. El dinero provendría de Craso (cada miembro del jurado parece haber recibido entre trescientos y cuatrocientos mil sestercios) y tanto Catulo ${ }^{41}$ como Cicerón ${ }^{42}$ se refieren a esta posibilidad. Además del posible soborno, el jurado puede haber estado temeroso, además de existir dudas acerca de la capacidad de Aurelia para reconocer a Clodio ${ }^{43}$. Puesto que la sentencia no fue la que Cicerón habría esperado y, lo que es peor, a través de su testimonio hizo de Clodio su enemigo mortal, lo que terminó en un vuelco trágico para su carrera -el exilio-, vale la pena subrayar los motivos que llevaron a Cicerón a tomar una actitud tan firme en la acusación. Cicerón mismo enfatizó las razones desinteresadas y puramente morales para este proceso ${ }^{44}$. En todo caso, en su primera relación de la profanación del ritual -descrita a Ático en una carta- no faltaba un cierto cinismo en el tono de la misma ${ }^{45}$. El describe la acción en contra de Clodio como uno de los pasos (subsecuentes) en el combate en contra de Catilina y alegó haber descubierto conexiones entre la conspiración de Catilina en el 63 y los elementos que apoyaban a Clodio en el juicio de la Bona Dea ${ }^{46}$. Esta explicación, en todo caso, no parece satisfactoria, puesto que Clodio había sido -como veremos- durante mucho tiempo un enemigo personal de Catilina y el mismo no había estado envuelto en su conspiración ${ }^{47}$.

Plutarco identifica la siguiente razón para que Cicerón diese su testimonio, que incriminaba a Clodio en el juicio de la Bona Dea: Cicerón había sido inducido por su mujer, Terencia, para que diese ese paso, cuyo odio estaba dirigido no tanto en contra de Clodio, sino de su hermana mayor, Clodia, por el hecho que Clodia

\footnotetext{
${ }^{38}$ Balsdon, John Percy Vyvian Darcre, cit. (n. 29), p. 71.

${ }^{39}$ Cicero, Epistulae ad Atticum 1,16,2; 2,1,5.

${ }^{40}$ Quintilianus, Institutio oratoria 4,2,88.

${ }^{41}$ Cicero, Epistulae ad Atticum 1,16,5; Dio Cassius, Historia Romana 37,46,3.

${ }^{42}$ Cicero, Epistulae ad Atticum 1,16,5.

${ }^{43}$ Balsdon, John Percy Vyvian Darcre, cit. (n. 29), p. 72.

${ }^{44}$ Cicero, Epistulae ad Atticum 1,18,2.

${ }^{45}$ Ibíd., 1,12,3.

${ }^{46}$ Ibíd., 1,14,5.

${ }^{47}$ Epstein, David F., Cicero's Testimony at the Bona Dea Trial, en Classical Philology, 80 (Chicago, 1986), p. 230.
} 
habría supuestamente querido que Cicerón se divorciase de Terencia y se casase con ella. A través del testimonio de Cicerón, Terencia habría querido deteriorar la relación, de manera que este paso no fuese dado y, por su parte, Cicerón querría estar libre de la sospecha. Plutarco mismo menciona esta posibilidad como un simple chismorreo de la ciudad y por ello es que los investigadores modernos han descartado esta versión ${ }^{48}$. En todo caso, igualmente vale la pena dar una mirada escrutadora a esta explicación también. Plutarco data la intención de Clodia respecto a Cicerón en el año 61. La cronología indicada por Plutarco es, a veces, incierta, pero los hechos que relata suelen ser históricos, a pesar de las imprecisiones temporales ${ }^{49}$. La historia parece más real si la situamos en el año 63 en lugar del 61. Luego de realizar un estudio de los matrimonios políticos realizados y planeados alrededor de esta época ${ }^{50}$, el matrimonio contraído por Clodia y Metello Céler puede ser ubicado hacia fines del $63^{51}$. A través del mismo, Metelo Céler entró al círculo de los optimates, y se convirtió en yerno del rival de Pompeyo, Lúculo. No puede excluirse que el partido de los optimates deliberadamente intentase alejar a Pompeyo de sus partidarios clave. En el 63, Cicerón, luego de haber tomado medidas en contra de los populares, se convirtió en un hombre de significado político para los optimates y es posible imaginar que en ese momento ellos intentasen vincularlo más próximamente a través del divorcio de Terencia y el matrimonio con Clodia. Y si después, el matrimonio, tan promisorio políticamente, no se llevó a cabo, debieron conformarse con Metelo Céler. Cicerón, probablemente, no quería romper su matrimonio por ventajas políticas temporales y tampoco consideraba el matrimonio político -usualmente utilizado en los altos círculos de Roma- como una carta de triunfo ${ }^{52}$. Sin embargo, si aceptamos esta hipótesis, la idea de Plutarco, de que Cicerón habría sido inducido por Terencia a testificar en contra de Clodio, parece fundada en una confrontación entre familias ${ }^{53}$.

El odio entre Terencia y Clodio viene del año 73, cuando Clodio acusó a Catilina de haber cometido incestum con Fabia. Ella era una virgo Vestalis medio hermana de Terencia. Gracias a la ayuda de Catulo, Catilina fue absuelto, aunque igualmente el caso daño profundamente a Fabia y, por tanto, a la familia de Terencia. Hay algunas referencias disponibles sobre el caso: así, por ejemplo, Salustio menciona el incestum como un hecho ${ }^{54}$, y una referencia al mismo también está contenida en la obra de Cicerón ${ }^{55}$. Presumiblemente, el ritual de la Bona Dea llevado a cabo en el 63 en la casa del entonces cónsul Cicerón, liderado por Terencia, dio un impulso a Cicerón para que tomase acción en contra de Catilina, puesto que los partícipes de la conjuración de Catilina ya se encontraban arrestados en

${ }^{48}$ Balsdon, John Percy Vyvian Darcre, cit. (n. 29), p. 72.

${ }^{49}$ Dorey, A. T., Cicero, Clodia, and the pro Caelio, en Greece and Rome, 5 (Cambridge, 1958), p. 179.

${ }^{50}$ Cf. Plutarchus, Cato minor 30; Pompeius 44.

${ }^{51} \mathrm{Cf}$. Cicero, Epistulae ad familiares 5,2,6.

${ }^{52}$ Dorey, A. T., cit. (n. 49), p. 179.

${ }^{53}$ Epstein, David F., (n. 47), p. 232.

${ }^{54}$ Sallustius, De coniuratione Catilinae 15,1.

${ }^{55}$ Cicero, In toga candida 82. 
Roma, aunque Cicerón no había tomado una decisión respecto a su destino. Las matronae que celebraban el ritual de la Bona Dea vieron el altar estallar en llamas, lo cual calificaba como prodigium, y fue interpretado por las virgines Vestales y Terencia (como líder de la festividad) como un aviso para que Cicerón tomara una acción firme en contra de los conspiradores para restaurar la pax deorum ${ }^{56}$. Las sacerdotisas y Terencia deben haber sido soliviantadas por el hecho que Fabia había sido humillada por Catilina, quien se había burlado de su reputación. La interpretación que alega que la profanación del festival de la Bona Dea en el 62 habría sido la respuesta política de Clodio a Cicerón por haberse dejado influenciar por la festividad del $63^{57}$ no parece fundada ${ }^{58}$. En primer término, porque Clodio no estaba entre los adherentes de Catilina; en segundo, porque es difícil presumir que él tenía un concepto político tan consiente.

Ambas, la hipótesis de los celos por un presunto plan de matrimonio con Clodia y el odio sentido por el hecho de haber sido Fabia humillada por Catilina y Clodio indican claramente que Terencia produjo una gran influencia en Cicerón respecto al testimonio que hizo en contra de Clodio. Clodio quería envolver a Terencia en la responsabilidad por las acciones de Cicerón. Al menos en el 58, como tribunus plebis él engañó a Cicerón ${ }^{59}$ para que no huyese de Roma -sólo para disfrutar más plenamente de su venganza ${ }^{60}$. Sin embargo, César le ofreció a Cicerón el puesto de legatus, para que pudiese dejar Roma. No está claro si esto sucedió antes ${ }^{61}$ o después ${ }^{62}$ de que Clodio fuese electo como tribunus. En todo caso, aunque estaba consciente del peligro, él no se fue ${ }^{63}$. Las consecuencias no previstas ni por Cicerón ni por Terencia son bien conocidas. En el 58 Clodio fue electo tribuno de la plebe. Para este fin, fue adoptado por una familia plebeya, lo cual fue llevado adelante con el consentimiento de César como pontifex maximus. Una vez elegido, sometió a votación al siguiente ley: cualquiera que hubiese provocado la ejecución de un ciudadano romano sin juicio debe ser proscrito. Esta ley (¡que fue promulgada con efecto retroactivo!) estaba dirigida en contra de Cicerón personalmente, quien había provocado la ejecución de cinco cómplices de Catilina en Tullianum durante la conjura Catilinaria sin procedimientos judiciales, aunque con la aprobación del Senado ${ }^{64}$. Cicerón partió al exilio y, el lugar donde estaba su casa en el Palatino, fue demolido. Clodio hizo construir ahí un templo para la diosa Libertas. Como destaca Imre Trencsényi-Waldapfel: "en la historia

\footnotetext{
${ }^{56}$ Plutarchus, Cicero 20,1-3.

${ }^{57}$ Benner, Herbert, Die Politik des P. Clodius Pulcher (Stuttgart, Steiner, 1987), p. 37; WiLl, Wolfgang, Der römische Mob (Darmstadt, Wissenschaftliche Buchgesellschaft, 1991), p. 48; Moreau, Philippe, Clodiana Religio. Un procès politique en 61 av. J-C. (Paris, Les Belles Lettres, 1982), p. 15.

${ }^{58}$ Spielvogel, Jörg, cit. (n. 37), p. 59.

${ }^{59}$ Plutarchus, Cicero 30,1-3.

${ }^{60}$ Epstein, David F., cit. (n. 47), p. 234.

${ }^{61}$ Cicero, Epistulae ad Atticum 2,18,3; 19,5.

${ }^{62}$ Dio Cassius, Historia Romana 38,15,2.

${ }^{63}$ Cicero, De provinciis consularibus 41-42.

${ }^{64}$ Uttschenko, Sergej Lvovi , Cicero (Berlin, Deutscher Verlag der Wissenschaften, 1978), p. 121; TrencsénYI-WaldAPFel, Imre, Cicero (Budapest, Gondolat, 1959), p. 43.
} 
mundial, no fue ni el primero ni el último acto cometido abusando del nombre de la libertad, aunque ciertamente fue uno de los más repulsivos" ${ }^{65}$. Puesto que ni Cicerón ni Terencia ${ }^{66}$ fueron capaces de prever las fatales consecuencias del testimonio realizado en el juicio de la Bona Dea que ocurrió en el 58, no puede ser considerado inconsistente de su parte el haber participado en la acción del 61, intentando compensar a través de ella a Fabia por la injuria sufrida por toda la familia en el 73.

\section{Situación RETÓRICA PROPICIAdA POR los “Ludi Megalenses”}

Luego de dar una breve cuenta histórico-política de la situación y las etapas de la relación hostil entre Cicerón y la gens Clodia, debemos volver nuestra atención a la situación retórica desarrollada en estas circunstancias y de cómo Cicerón trata el problema. De Saint-Denis dice que la Pro Caelio es el más agudo de los discursos de Cicerón ${ }^{67}$. Esto, ya se desprende de la fecha en que el discurso fue realizado (4 de abril), que coincide con el primer día de los Ludi Megalenses, lo que le permite explotar las contradicciones propias de la situación a través del humor $^{68}$. Los Ludi Megalenses (4-10 de abril) era la festividad de la Magna Mater (Kybel ), cuyo culto fue introducido en Roma en 205/4, inmediatamente después de la Segunda Guerra Púnica, en base a los dictados contenidos en los libri Sibyllini ${ }^{69}$. Solicitaron su importación al presidente del culto, entonces Atalo, rey de Pérgamo, quien envió la piedra negra que representa a la diosa y equipó un barco para llevarla a Roma ${ }^{70}$. Según otra tradición, la piedra fue llevada a Roma directamente desde Pessino ${ }^{71}$. La diosa fue traída a Roma con la ceremonia ritual. El Senado confió a Escipión Nasica la recepción de la Magna Mater. Ciertas fuentes señalan que, a fin de probar su inocencia, la sacerdotisa de Vesta, Quinta Claudia, puso a navegar por sí misma el barco que transportaba la piedra, el cual estaba atrapado en un banco de arena del Tíber $^{72}$. Por ello, en su templo en el Palatino, también fue erigida una estatua a Claudia ${ }^{73}$. Este templo fue terminado en el 191 y fue en esta ocasión que los juegos Megalensia y las obras de teatro (ludi scaenici) fueron introducidos.

En el ritual de los Ludi Megalenses -como en todo el culto romano de Ci-

${ }^{65}$ TRENCSÉNYI-WALDAPFel, Imre, cit. (n. 64), p. 43.

${ }^{66}$ Cf. Cicero, Pro Caelio 50; Epistulae ad Atticum 14,2,2.

${ }^{67}$ SaInt Denis, Eugène de, Le plus sprituel des discours cicéroniens: le Pro Caelio, en SAINT DenIS, Eugène de, Essais sur le rire et le sourire des Latins (Paris, Les Belles Lettres, 1965), pp. 129.

${ }^{68}$ Salzman, Michele R., Cicero, the Megalenses and the Defense of Caelius, en American Journal of Philology, 103 (Baltimore, 1982), p. 301.

${ }^{69}$ LaTte, Kurt, cit. (n. 21), p. 258.

${ }^{70}$ Livius, Ab urbe condita 29,10; 4,14,5; Ovidius, Fasti 4,255; Silanus, Punica 17,1; ApPIANUS, Hannibalica 233.

${ }^{71}$ CiCERo, De haruspicum responso 27; LIVIUS, Ab urbe condita 29,10,7; STRABO, Geographica 12,567; Ammianus Marcellinus, Res gestae 22,9,5.

${ }^{72}$ Suetonius, Tiberius 2,3; Lactantius, Divinae institutiones 2,7,12.

${ }^{73}$ Tacitus, Annales 4,64. 
beles- se excluyó la furiosa danza gala, que representaba la automutilación de Attis $^{74}$. Por otro lado, los hallazgos arqueológicos acreditan la aparición del culto de Attis simultáneamente con el culto de la Magna Mater, toda vez que en las excavaciones en el Palatino de 1950/1 fueron encontradas pequeñas estatuas que representaban a Attis en la capa Templo de Cibeles correspondiente al siglo II a.C. Estos hallazgos refutan la opinión según la cual el culto de Cibeles habría sido tomado e introducido a Roma sin el culto de Attis ${ }^{75}$, basándose simplemente en dudosas hipótesis filológicas ${ }^{76}$.

Como ya se ha señalado, desde un comienzo se desarrollaban representaciones teatrales en los Megalensia. Aparte de destacar que dos miembros de la gens Claudia se veían directamente afectados en el juicio y del contraste entre Clodia y Quinta Claudia ${ }^{77}$, existía otro vínculo entre los Megalensia y la historia familiar de los Clodios. Clodio había perturbado el festival de la Magna Mater en repetidas oportunidades. El causó un segundo escándalo sea en el 8, 9 o 10 de abril del $56^{78}$, cuando, acompañado por esclavos armados, él atacó y ocupó el teatro donde se desarrollaban las representaciones ${ }^{79}$. Esto ocurrió sólo unos pocos días después de que la Pro Caelio fuese entregada, pero, en todo caso, aquéllos que escuchasen el discurso pueden haber pensado, y muy probablemente así lo hicieron, en el primer incidente, puesto que en el 58 Clodio estuvo envuelto en una acción en contra del santuario de Cibeles en Pessino ${ }^{80}$, cuando Brogitarus, que apoyaba la banda armada de Clodio con dinero, obtuvo la dignidad de sacerdote de Cibeles (junto con un título real) en Pessino, contando con la ayuda de Clodio para expulsar al legítimo detentador del título y quebrantar el culto ${ }^{81}$. En este sentido, la gens Clodia estaba vinculada a los Megalensia tanto por su historia, como por problemas de política contingente.

\section{Tácticas retóricas de la "Pro Caelio”}

Al comienzo de su discurso, Cicerón hace como si se lamentara porque los jueces no puedan descansar ni siquiera en los días de fiesta ${ }^{82}$, ni ver las representaciones teatrales que se desarrollan en ese mismo momento. Por eso, el orator irá al escenario para realizar su propia actuación, una comedia, donde Clodia, la fuente de la acusación, estará en el centro del escenario ${ }^{83}$. Al hacerlo, no trata de mejorar la opinión de los jueces respecto al acusado, sino que lleva al centro del

\footnotetext{
${ }^{74}$ LatTe, Kurt, cit. (n. 21), p. 260.

${ }^{75}$ Altheim, Franz, Römische Religionsgeschichte (Berlin, Göschen, 1932), II, p. 51.

${ }^{76}$ Graillot, Henri, Le culte de Cybèle, Mère des Dieux à Rome et dans l Empire romain (Paris, Pontemoing, 1912), p. 101.

${ }^{77}$ Cicero, Pro Caelio 34.

${ }^{78}$ SAlZman, Michele R., cit. (n. 68), p. 303.

${ }^{79}$ Salzman, Michele R., cit. (n. 68), p. 303.

${ }^{80}$ Cicero, De harispicum responso 27.

${ }^{81}$ Ibíd., 28.

${ }^{82}$ Cicero, Pro Caelio 1.

${ }^{83}$ Ibíd., 2.
} 
asunto las motivaciones de sus oponentes, opes meretriciae, ${ }^{84}$ y no hay ninguna duda que aquéllos que escuchan el discurso saben a quien el término meretrix se aplica: la testigo clave de la acusación de intento de homicidio contra Dión, la viuda alegre romana, Clodia Metela, bien conocida por su vida licenciosa. Antes de responder a los cargos (de vi), el considera importante responder a toda las falsas imputaciones difamatorias hechas en contra de Celio ${ }^{85}$

De la parte que concierne a la vita ante acta $^{86}$, los siguientes cargos clave pueden distinguirse. Celio habría violado la pietas y la fides, al no otorgar el debido respecto a su padre ${ }^{87}$, y no habría actuado correctamente en lo referente a Calpurnio Bestia tampoco, cuando provocó su comparecencia ${ }^{88}$. En cuanto al cargo de luxuria, ${ }^{89}$ él se lo reprochó tanto a Herenio como a Clodio no debiendo ellos imputárselo a Celio ${ }^{90}$, como también el de tener una vida disoluta durante su juventud $^{91}$. También existieron otros cargos de naturaleza política, como el tener una relación amistosa con Sergio Catilina ${ }^{92}$, el supuestamente haber participado en su conspiración ${ }^{93}$, el crimen de ambitus $^{94}$ y el haber atacado a un senador en la elección de pontifex $x^{95}$. La agrupación de los cargos parece arbitraria, pero su orden sigue, en su mayor parte, el curso de la vida de Celio ${ }^{96}$. La tercera parte ${ }^{97}$ discute el cargo de asesinato en contra de Dión. Esta acusación se sostiene en la declaración de Clodia. Ella alega que Celio habría obtenido dinero de ella para sobornar a los esclavos de Lucceyo y que después, habría intentado deshacerse de ella por ser una testigo incriminatoria ${ }^{98}$.

Cicerón divide la declaración de Clodia en dos acusaciones independientes ${ }^{99}$, para así, refutar el cargo de aurum $^{100}$ y de venenum ${ }^{101}$ separadamente $^{102}$. Uno de los objetivos claramente perceptibles de Cicerón es alivianar la carga política del juicio lo más posible y es por esta razón que no se centra en el ataque que ha sufrido Dión. El crimen veneni es bien conocido. Presumiblemente, también existían otros testimonios para apoyar la declaración de Clodia de que Celio habría intentado entregarle veneno a sus esclavos. Es muy interesante que en todo su discurso

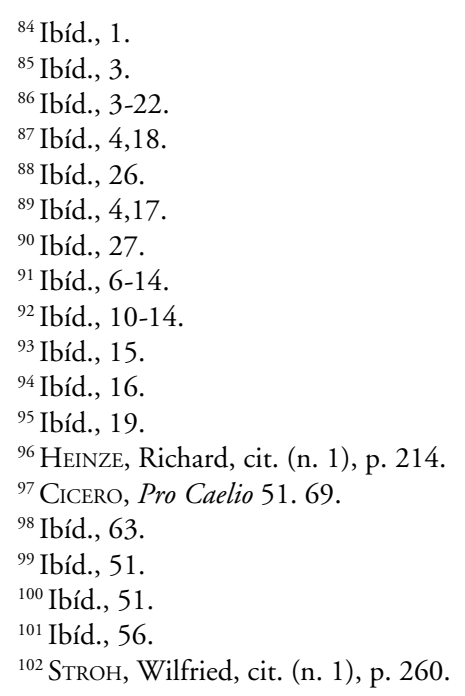


Cicerón no ofrezca ninguna versión alternativa, sino que parece satisfecho con destacar las inconsistencias en el petitorio de sus oponentes para hacerlo parecer ridículo, como también enfatizando que el corpus delicti no se encuentra disponible. Aunque así no logra desarticular completamente la sospecha que pesa sobre Celio, al menos consigue sacar este detalle de su contexto original ${ }^{103}$.

Muchas preguntas materiales surgen en la parte media del discurso ${ }^{104}$. Luego de haber cubierto los parágrafos de vita, o de moribus, el orator conduce la atención hacia los cargos propuestos en la acusación. Con pocas palabras él brevemente presenta el asesinato de Dión. Él señala que el rey Tolomeo sería el autor del homicidio, quien se habría servido de Asicio, el que, en el intertanto había sido absuelto por haber actuado sólo como una herramienta. Por esta razón, ni aún la sombra de una sospecha podría recaer sobre Celio ${ }^{105}$. Luego de esto, repentinamente vuelve sobre las objeciones que se habrían hecho acerca de la conducta de Celio (deliciarum obiurgatio) ${ }^{106}$. Con respecto a ciertas licencias menores, el toma un punto de vista liberal, afirmando que la juventud tiene el derecho a llevar una vida despreocupada, mientras no dañen a nadie ${ }^{107}$. Con respecto a casos más serios, le pide a los jueces que distingan entre el objeto de la acusación (res) y el defendido (reus) o, en otras palabras, que sean conscientes que las objeciones levantadas conciernen a toda la juventud de su tiempo y no específicamente a Celio $^{108}$. Entonces pasa a tratar el un caso que definitivamente constituye un crimen luxuriae: el dinero obtenido de Clodia permite deducir la existencia de una relación íntima, la cual habría terminado con una separación amarga ${ }^{109}$. En lugar de continuar por la línea a primera vista lógica (por un lado, él podría negar la existencia de este amorío o, por otra, el podría dudar completamente de la autenticidad de ambos crimina debido al súbito quiebre en la relación), Cicerón elige seguir un camino distinto: en lo que sigue ${ }^{110}$, el pone en duda el testimonio de Clodia sobre la base de que al ser amante abandonada y celosa, ella no es capaz de juzgar a Celio sin bias. De esta manera, el anticipa el tema de vi que pertenece a la argumentatio $^{111}$. De esta manera, vis y luxuria se intercambian en los parágrafos sucesivos: 23-50: ${ }^{112}$ vis, ${ }^{113}$ luxuria,${ }^{114}$ vis, ${ }^{115}$ luxuria,${ }^{116}$ vis. ${ }^{117}$

Este punto es destacado en una excelente observación hecha por Heinze, cuan-

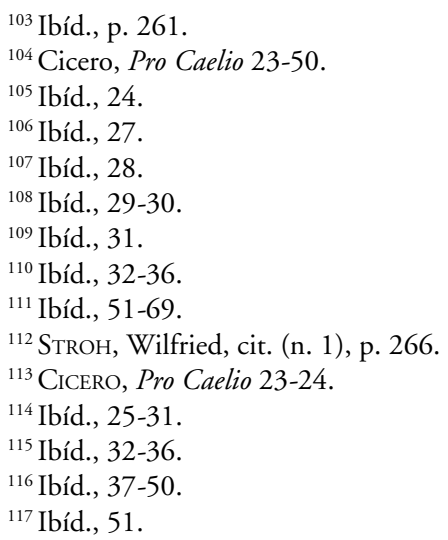


do él afirma que la construcción de la acusación está primaria y exclusivamente fundada en el testimonio de Clodia. Por tanto, su autenticidad podría arruinarse al presentar a Clodia como la amante abandonada de Celio. Consecuentemente, era Cicerón el más apropiado para sacar esta relación a relucir en el juicio ${ }^{118}$. Por tanto, él defendió a Celio en contra de una acusación (puesto que la relación con Clodia está más allá de ser tan general como para ser simplemente amores y libidines) que no había sido interpuesta en su contra ${ }^{119}$. Toda la cuestión parece más apropiada, puesto que no hay ni un punto en toda la Pro Caelio donde Cicerón presuma que la relación amorosa entre Clodia y Celio sea un hecho conocido para el público que escucha el caso. En varios lugares el menciona ciertos rumores generalmente difundidos acerca de la vida sexual de cada uno separadamente, pero nunca respecto a la relación entre ellos. Por tanto, es el propio Cicerón quien reduce la conducta licenciosa desarrollada por Clodia y Celio individualmente aun común denominador e inventa la conexión entre ellos ${ }^{120}$. La situación habría sido explotada por un abogado defensor menos genial que Cicerón de la siguiente manera. Primero, él habría disminuido la importancia del crimen de luxuriae apuntado la naturaleza general de los cargos y el derecho de los jóvenes a llevar una vida libre. En segundo lugar, habría intentado poner en duda la autenticidad del testimonio de Clodia -lo que tal vez no fuese difícil, puesto que en 56 poemas satíricos aparece llevando una relación incestuosa con su hermano Clodio y éstos estaban más bien difundidos entre el pueblo ${ }^{121}-\mathrm{y}$, así, el habría cuestionado si es que un tribunal romano podía dotar de valor al testimonio de una meretrix. Este orator menos genial que Cicerón, como hemos dicho, habría tenido que enfrentar las siguientes dificultades: primero, ¿cómo aceptar que mida por dos varas distintas? Esto es, ¿por qué sería tan laxo respecto a la lascivia de Celio y tan estricto respecto a la de Clodia? Es un hecho que Celio es sólo un joven, mientras que Clodia es la viuda de un cónsul, pero todo el discurso se tornaría poco auténtico por esta dualidad. Incluso si Clodia, por su conducta, no fuese considerada un testigo suficientemente fehaciente, esto no daría ninguna razón para considerarla mentirosa. Y, en el conjunto, no aparecería ninguna razón para dar falso testimonio en contra de Celio ${ }^{122}$

Es a través de esta construcción brillante que Cicerón le quita el aguijón a toda posible objeción. ¿Cómo se vería el caso si Clodia hubiese sido la amante de Celio? El filo de las aversiones morales en contra de Celio se elimina por el hecho de no ser posible cometer adulterium con una mujer como Clodia, toda vez que estaría entre los amores meretricii. Y la razón para la declaración de Clodia se soluciona de un solo golpe: la amante despechada está sedienta de venganza y es por esta razón que ella levantaría un falso testimonio, por lo que subsecuentemente, este no debiese ser considerado. Por otro lado, Cicerón carece de un fondo suficientemente extenso para construir una relación entre Clodia y Celio: ambos viven

\footnotetext{
${ }^{118}$ Heinze, Richard, cit. (n. 1), p. 228.

${ }^{119}$ Ibíd., p. 245.

${ }^{120}$ STroH, Wilfried, cit. (n. 1), p. 272.

${ }^{121}$ Cicero, Ad Quintum fratrem 2,3,2.

${ }^{122}$ STroH, Wilfried, cit. (n. 1), p. 274.
} 
en el Palatino y ninguno es conocido por llevar una vida ascética. En todo caso, Cicerón encuentra un punto más: la acusación señala que Clodia le habría dado dinero a Celio, quien más tarde habría intentado envenenar a Clodia (aurum et venenum). De acuerdo a la construcción de Cicerón, que parece bastante obvia, todo esto ha sucedido por la relación íntima que han llevado y el quiebre tormentoso entre ellos. En todo caso, aún así parece difícil resolver el dilema: las alegaciones hechas en la acusación o bien son verdaderas y Celio es culpable del asesinato de Dión, o bien, si son falsas, entonces el vínculo entre Celio y Clodia no puede ser desarrollado. Por tanto, Cicerón debe absolver al acusado (luxuria), y convertir el testimonio de Celia en poco fiable (vis). Si la relación entre ambos hubiese sido ampliamente conocida, entonces Cicerón debería haber tenido que centrarse en el tema de la luxuria en la parte dedicada a de vita ac moribus, y en el ataque en contra de Clodia en la parte relativa al crimen de vi. De esta manera, en todo caso, él trata de la falta de autenticidad de Clodia bajo los puntos de los crimina auri et veneni, construyendo y manipulando la relación entre Clodia y Celio ${ }^{123}$.

Ahora, consideremos la forma en que Cicerón crea esta relación. Al comienzo de su discurso ${ }^{124}$ el no nombra a Clodia, sino que sólo se refiere a las opes meretriciae, lo que propiamente rima con "intolerabilis libido" y "nimis acerbum odium"125. Cuando habla de la mudanza de Celio al Palatino, él lo formula más claramente ${ }^{126}$. Aquí, Cicerón usa la bien conocida historia de Medea, que ha salido algunas veces antes en la demanda, ya que Atratino llamó a Celio pulchellus Iason, refiriéndose a la historia del vellocino de oro, por el dinero a él prestado ${ }^{127}$, mientras que Celio respondió llamando a Atratino Pelia cincinnatus ${ }^{128}$. Él entonces se refiere al tema de la relación entre el dinero y el veneno ("duo sunt autem crimina, auri et veneni") en función del tema de la luxuria e intenta sacar conclusiones acerca de ello respecto a la relación entre Clodia y Celio. Sin embargo, si él hubiese pronunciado estas expressis verbis, entonces él estaría aceptando que los cargos son verdaderos ${ }^{129}$.

Cicerón repite las acusaciones de su oponente agregando la frase ut dicitur, pero deja que ellos parezcan verdaderos -o, más propiamente, él suspende la respuesta a dar acerca de ellos- mientras ellos calcen con sus propósitos ${ }^{130}$. Es aquí donde invoca a Apio Claudio el Ciego (prosopopoiia) del inframundo -la que en ningún caso es una herramienta que pertenezca al genus grande ${ }^{131}$ en el presente

${ }^{123}$ Ibíd., p. 275.

${ }^{124}$ Cicero, Pro Caelio 1.

${ }^{125}$ Ibíd., 2.

${ }^{126}$ Ibíd., 18: "Quo loco possum dicere id quod vir clarissimus, M. Crassus, cum de adventu regis Ptolemaei quereretur, paulo aute dixit: 'utinam ne in nemore Pelio...' ac longius mihi quidem contextere hoc carmen liceret: 'nam numquam era errans' hanc molestiam nobis exhiberet 'Medea animo aegro, amore saevo saucia' [...]”.

${ }^{127}$ MÜNZER, Friedrich, cit. (n. 11), p. 136.

${ }^{128}$ Quintilianus, Institutio oratoria $1,5,61$.

${ }^{129} \mathrm{~S}$ TroH, Wilfried, cit. (n. 1), p. 278.

${ }^{130}$ Cicero, Pro Caelio 30-32.

${ }^{131}$ Quintilianus, Institutio oratoria $12,10,61$. 
caso $^{132}$, sino un truco lleno de comicidad ${ }^{133}$ - a fin de poder comparar las antiguas virtudes romanas con el estilo de vida de Clodia. Aparentemente, esto no sirve de defensa, puesto que el ancestro conjurado está convencido de la veracidad del cargo de aurum et venenum ${ }^{134}$. En todo caso, el discurso del viejo censor retroalimenta tanto la existencia de una relación entre Clodia y Celio, como corrupción de Clodia en las mentes de los jueces ${ }^{135}$.

Luego de esto, la reprehensio testis puede ser implementada con respecto a Clodia, presentándola como una amante abandonada y celosa, lo que prueba que Celio no es un adulter, sino sólo un amator, un amante. De acuerdo con el elenco anterior (primero Cicerón mismo y luego Apio Claudio el Ciego han supuestamente hablado), aquí nuevamente el orador toma la voz y luego Clodio Pucher. De esta manera, Cicerón carga el peso de la prueba en quienes han sido invocados. En este punto la táctica de Cicerón se aclara: si el cargo de veneno y oro es verdadero, entonces Clodia era la amante de Celio; si ella era su amante, entonces su testimonio no tiene valor, por lo que el cargo de veneno y oro no se ha probado. Así, el cargo de veneno y oro, que ha sido invocado por Cicerón a fin de hacer plausible la "liaison", se hace innecesario y, por tanto, debe ser dejado de lado sin que se note, para que los jueces no recuerden en qué premisas se han basado sus conclusiones ${ }^{136}$. Los crimina auri et veneni están fusionados con el crimen luxuriae, y en el resto del discurso son tratados así. En el discurso puesto en boca de Clodio es asumido como un hecho que Clodia es la amante de Celio -mientras que Apio Claudio dedujo esto de varios elementos sospechosos ${ }^{137}$. El nivel de información que manejan ambos se corresponde con el nivel de conocimiento del auditorio. Clodio detalla el asunto de manera más bien laxa -y ahí Cicerón le da un golpe mortal a la confesión de Clodia ${ }^{138}$.

En la edición de los parágrafos 30-36 de la Pro Caelio podemos ver varias líneas que corren paralelas. En términos de contenido: la deducción hipotética desde el oro y el veneno a la existencia de una relación y una separación (aquí el narrador es Cicerón) ${ }^{139}$, la conclusión (real ahora, no hipotética), donde el narrador es Apio Claudio el Ciego ${ }^{140}$, la conclusión hipotética desde la relación y la ruptura acerca de la invalidez del testimonio de Clodia (aquí el narrador es nuevamente Cicerón) ${ }^{141}$ y la conclusión final esquematizada por Clodio ${ }^{142}$. En cuanto al propósito real de demostrar la evidencia: la prueba de la existencia de

\footnotetext{
${ }^{132}$ Geffcken, Kathrine, Comedy in the pro Caelio (Leiden, Brill, 1973), p. 18.

${ }^{133}$ Cf. Cicero, Pro Caelio 33.

${ }^{134}$ Ibíd., 33-34.

${ }^{135}$ StroH, Wilfried, cit. (n. 1), p. 282.

${ }^{136}$ Cicero, Pro Caelio 35.

${ }^{137}$ Ibíd., 36.

${ }^{138}$ STroH, Wilfried, cit. (n. 1), p. 284.

${ }^{139}$ Cicero, Pro Caelio 30-32.

${ }^{140}$ Ibíd., 33-34.

${ }^{141}$ Ibíd., 35.

${ }^{142}$ Ibíd., 36.
} 
una relación ${ }^{143}$ que arruina la verosimilitud de Clodia ${ }^{144}$. En relación a lo que los hechos aparentemente demuestran: la inocencia de Celio respecto al crimen luxuriae ${ }^{145}$, lo cual desacredita a Clodia ${ }^{146}$. Luego de esto, él libera a Celio del ser caracterizado como un adulter, toda vez que ha demostrado que Clodia está viviendo una vida impropia de una matrona, por lo que no es posible cometer adulterium con tal tipo de mujer, que no es otra cosa que una meretrix. Aunque en este último punto ${ }^{147}$ Cicerón no nombra a Clodia y la formulación de juicio es, en alguna medida, hipotética, más adelante el señala que Clodia vive meretricio more ${ }^{148}$. A través de esta afirmación, el orador se adapta a las ideas de dos distintos tipos de padres que están envueltos en el proceso. Ambos tipos de padres están de acuerdo ${ }^{149}$ en que a los jóvenes siempre se les ha permitido llevar una conducta algo libidinosa y que esta vida libertina puede incluir el mantener relaciones con mujeres como Clodia, ya que pertenece al ámbito de los amores meretrici $i^{150}$. Al presentar la relación con Clodia, Cicerón usa las herramientas retóricas del humor y la ironía en varias oportunidades. Por ello, parece adecuado considerar qué rol juegan éstos como herramientas del orador en la teoría de la elocución en la Antigüedad y, especialmente, en el Corpus Ciceronianum. La utilidad de la risa - geloion - fue expuesta por Gorgias por, quien señalaba que la seriedad del oponente debía ser contrastada con la risa y la burla a fin de mermar su impacto ${ }^{151}$, según lo cita Aristóteles, que parece estar de acuerdo ${ }^{152}$. Es en este punto donde Aristóteles se refiere al hecho que en la Poetica él ya ha expuesto cuántos tipos de geloion hay, aunque la parte de la Poetica donde se discute la comedia se ha perdido. Él agrega que parte de esto es apropiado para un hombre libre, mientras que otra no lo es, por lo que un orador debe usar la primera ${ }^{153}$. El hecho que varios autores griegos han tratado acerca del humor se encuentra mencionado en los escritos de Cicerón ${ }^{154}$. Estos escritos, en todo caso, no se han conservado. Quintiliano aprecia dos grandes diferencias entre las dos más grandes figuras de la elocuencia en la Antigüedad, Demóstenes y Cicerón, en lo relativo a su sentido del humor: mientras que a Demóstenes le faltaba altura de espíritu, Cicerón podía mantener a raya su ingenio ${ }^{155}$. En el Orator $^{156}$ Cicerón toca el tema

\footnotetext{
${ }^{143}$ Ibíd., 30-34.

${ }^{144}$ Ibíd., 35-36.

${ }^{145}$ Ibíd., 30-31.

${ }^{146}$ Ibíd., 32-36.

${ }^{147}$ Ibíd., 38. 49.

${ }^{148}$ Ibíd., 57.

${ }^{149}$ Ibíd., 37.

${ }^{150}$ StroH, Wilfried, cit. (n. 1), p. 289.

${ }^{151}$ Gorgias, fragmenta $82 \mathrm{~b} ; 12 \mathrm{~d}-\mathrm{k}$

${ }^{152}$ Aristoteles, Rhetorica 3 - 1419b

${ }^{153}$ Ibíd., 3 - 1419b

${ }^{154}$ Cicero, De oratore 2,217; Quintilianus, Institutio oratoria 6,3,5; BARWICK, Karl, Das rednerische Bildungsideal Ciceros (Berlin, Akademie-Verlag, 1963), p. 73.

${ }^{155}$ Quintilianus, Institutio oratoria 6,3,1-3; CiCERo, Orator 26,90.

${ }^{156}$ Cicero, Orator 87.
} 
y da una exposición exhaustiva ${ }^{157}$ acerca del problema del ingenio, las bromas y el humor. Como fuentes el utiliza su propia práctica, algunas colecciones de chistes romanos ${ }^{158}$ y los escritos peripatéticos ${ }^{159}$. Su amanuense, Tiro, publicó un thesaurus de ejemplos reunidos en tres libros acerca del tema.

Cicerón comienza el tratamiento afirmando que las bromas y el humor son, frecuentemente, muy útiles ${ }^{160}$. Luego, continúa señalando que él mismo ha visto en demandas judiciales conseguirse todo tipo de cosas a través del ingenio ${ }^{161}$. Cicerón busca respuestas para cinco questiones relativas a la risa. ¿Qué es la risa? ¿De dónde viene? ¿Debe el orador buscarla creación de alegría? ¿Hasta dónde puede llegar? ¿Cuántos tipos de ridiculum existen ${ }^{162}$ ? Uno de los protagonistas del diálogo, C. Julio César Estrabón clama que la primera pregunta no pertenece al tema ${ }^{163}$, mientras que respecto a la segunda, la responde citando a Aristóteles al decir que ridiculum debe ser aplicado en un campo determinado por los atributos: lo feo y lo grotesco ${ }^{164}$. A la tercera pregunta, la respuesta es claramente afirmativa ${ }^{165}$. A la cuarta pregunta él responde de la siguiente manera: el orator no debe burlarse ni del retraso mental ni de las graves desgracias ${ }^{166}$; similarmente, una persona favorecida y respetada por el público, no debiese convertirse en blanco de la burla ${ }^{167}$. La ley básica en todo esto es la moderación ${ }^{168}$. De la respuesta a la quinta pregunta, se entiende que una de los tipos de broma es creado por la cosa en sí, mientras que otro se inventa a través de la formulación ${ }^{169}$. Luego de esto, él identifica las fuentes del ridiculum a las que el orador puede recurrir ${ }^{170}$ y a cuales no ${ }^{171}$. La risa es evocada, por ejemplo, cuando el orador dice algo que nadie espera; en este caso nos reímos de su propio error ${ }^{172}$. Al definir al perfectus orator Cicerón identifica tres estilos - simple, medio y sublime - y señala que aunque algunas personas son excelentes en algún estilo específico, muy pocas los dominan todos ${ }^{173}$. En Orator Cicerón entrega los fundamentos teóricos de los tres tipos de estilo y apunta que, junto con los demás atributos (evitar el ritmo de la prosa y las frases complejas, abandonar el hiatus, la munditia y la elegantia, la moderación en la aplicación de

${ }^{157}$ Ibíd., 2,216-289.

${ }^{158}$ Ibíd., 2,271.

${ }^{159}$ Acerca de este tema, véase: ARNDT, Ernst Mauritz, De ridiculi doctrina rhetorica (diss. Bonn, 1904).

${ }^{160}$ Cicero, De oratore 2,216.

${ }^{161}$ Ibíd., 2,219.

${ }^{162}$ Ibíd., 2,235.

${ }^{163}$ Ibíd., 2,235.

${ }^{164}$ Ibíd., 2,236; Acerca de este tema, véase: CoOper, Lane, An Aristotelian Theory of Comedy

(New York, Hancourt, 1922).

${ }^{165}$ Cicero, De oratore 2,236.

${ }^{166}$ Ibíd., 2,237.

${ }^{167}$ Ibíd., 2,237.

${ }^{168}$ Ibíd., 2,238; QuINTILIANUs, Institutio oratoria 6,3,28-31.

${ }^{169}$ Cicero, De oratore 2,240.

${ }^{170}$ Ibíd., 2, 269; 280; 289.

${ }^{171}$ Ibíd., 2,251.

${ }^{172}$ Ibíd., 2,255.

${ }^{173}$ Cicero, Orator 20. 
ornamentos, palabras y figuras), lo más característico del estilo simple es el ingenio y el uso de una lengua afilada. Cuando el orador los usa, debe asegurarse de causar un daño irreparable y reservar el aguijón sólo para sus enemigos, con moderación y sin herir. Él llama a esto el más puro aticismo, aunque en este respecto, ninguno de los aticistas recientes ha alcanzado especial elegancia ${ }^{174}$.

Varios elementos esenciales de la comedia romana han sido destacados por Segal, quien alega que, casi como una perfecta oposición entre la vida cotidiana de Roma, regida por el negotium y la industria, aparece el denominado día Plautino donde los atributos clave son el ludus y la voluptas ${ }^{175}$. Durante el período en funciona el teatro, la actividad en el forum se suspende (Ludi Romani, Ludi Apollinares, Ludi plebei, Ludi Megalenses), por lo que constituyen una especie de excepción a la gravitas que permea toda la vida romana. En las comedias, cada protagonista sale del mundo de lo cotidiano: los jóvenes no obedecen a su padre, las matronae no se someten a la voluntad de su marido y los esclavos estafan a sus amos sin ser castigados. A veces se busca educar a los elementos foráneos, quienes serán integrados en la sociedad si aceptan la crítica, mientras que serán definitivamente expulsados si mientras se desarrolla la obra continúan siendo extraños $^{176}$. Las personas atacadas por el humor de Plauto suelen ser del tipo milites gloriosi o los conservadores del estilo de Catón el Viejo, figuras puritanas. En las obras de Terencio, la oposición entre padres estrictos e hijos alegres es un motivo bastante frecuente (la mayor parte de los padres "mejoran" y comienzan a tolerar la conducta de sus hijos) ${ }^{177}$. En el Pro Caelio ${ }^{178}$, en la syncresis de los dos tipos de padres, Cicerón cita las palabras de dos padres de las comedias de Cecilio y Terencio. El primero es severo y estricto, mientras que el segundo es bien intencionado y tolerante. No es casualidad que la cita venga del discurso de Micio en Adelphoe. ${ }^{179}$ Las palabras de los dos padres pueden, hasta cierto punto, ligarse con los dos actores conjurados en los parágrafos precedentes: Apio Claudio el Ciego y P. Clodio Púlcher, creando un paralelo con la relación entre Cicerón y su hijo intelectual/espiritual, Celio, la cual constituye un evidente opuesto respecto a la relación entre Clodia y su más joven hermano/marido, Clodio $^{180}$.

En la caracterización de Clodia, el orador cita la tragedia de Enio titulada $\mathrm{Me}$ dea exul, y usa los versos con un tono trágico que produce un impacto cómico ${ }^{181}$. Es así como Celio se convierte en Jasón, su mudanza al barrio de Clodia-Medea en un viaje mitológico y la viuda alegre abandonada en una hechicera ${ }^{182}$. Más adelante, él presenta la aventura de entregar un frasco no tanto dentro del espíritu de la comedia, como en el de la mímica ${ }^{183}$. En este tipo de obras (y esto es

\footnotetext{
${ }^{174}$ Ibíd., 89.

${ }^{175}$ SEGAL, Erich, Roman Laughter (Cambridge, Cambridge University Press, 1968), p. 42.

${ }^{176}$ FrYe, Northorp, Anatomy of Chriticism (New York, Schocken, 1969), p. 163.

${ }^{177}$ SegAL, Erich, cit. (n. 175), p. 70.

${ }^{178}$ Cicero, Pro Caelio 37-38.

${ }^{179}$ Terentius, Adelphoe 120-121.

${ }^{180}$ GeFFCKEN, Kathrine, cit. (n. 132), p. 23.

${ }^{181}$ Cf. Quintilianus, Institutio oratoria 8,6,53.

${ }^{182}$ GefFCKEN, Kathrine, cit. (n. 132), p. 15.

${ }^{183}$ Cicero, Pro Caelio 61-69.
} 
relevante en la caracterización de Clodia como meretrix) las prostitutas accedían al escenario ${ }^{184}$. El tipo “comedia dell' arte mimus", al no tener una verdadera historia, estaba lejos de constituir una forma de entretenimiento para mejorar los estándares morales, y frecuentemente producía un impacto expresado en la risus mimicus a través de la obscenidad. El adulterio y el intento de envenenamiento eran los cimientos de su trama; de la misma manera, Cicerón describe lo ocurrido en los baños como una obscenissima fabula ${ }^{185}$. Él presenta los eventos dirigidos a la entrega y la obtención de la pyxis como muliebre bellum, en el curso de los cuales Clodia se convierte en imperatrix y sus hombres en provincia que ocultan el caballo de Troya ${ }^{186}$. La caracterización de Clodia como meretrix ${ }^{187}$ constituye el contraste perfecto con la imagen de la obediente matrona que cuida la pureza de su hogar. La conducta y apariencia de Clodia encaja con el de una meretrix y no con el de una mater familias ${ }^{188}$, sus familiaris son los esclavos y el amo de los baños ${ }^{189}$, y respecto a este punto, Cicerón saca a colación su sobrenombre quadrantaria dos veces ${ }^{190}$. Plutarco señala que este título le habría sido impuesto porque sus amantes solían darle un quadrans como pago ${ }^{191}$, y él menciona a Celio por el sobrenombre de Quadrantaria Clytaemnestra ${ }^{192}$. Celio es atacado por opibus meretriciis ${ }^{193}$, ayudado por prostitutas; así, Clodia lidera su ejército como una especie de miles gloriosa ${ }^{194}$.

En la carrera de Cicerón existieron muchos más momentos de triunfo y algunos que incluso hicieron historia. Sin embargo, como tal vez se ha hecho evidente de las referencia hechas aquí, hubo pocos momentos cuando como orador él pudo presentar tan brillantemente una verdadera obra de teatro tan genialmente construida, como a los jueces en el Megalensia del año 56. El discurso logró alcanzar los resultados deseados: Celio fue encontrado inocente y la demanda otorgó a Cicerón la oportunidad de vengarse -aunque sólo verbalmente y de forma parcial- de las ofensas cometidas por Clodio y Clodia en su contra.

\section{BibLIOGRAFÍA}

Altheim, Franz, Römische Religionsgeschichte (Berlin, Göschen, 1932).

ARndT, Ernst Mauritz, De ridiculi doctrina rhetorica (diss. Bonn, 1904).

BalsDon, John Percy Vyvian Darcre, Fabula Clodiana, en Historia. Zeitschrift für alte Geschichte, 15 (Stuttgart, 1966).

\footnotetext{
${ }^{184}$ Lactantius, Divinae institutiones $1,20,10$

${ }^{185}$ Cicero, Pro Caelio 69.

${ }^{186}$ GeffCKen, Kathrine, cit. (n. 132), p. 25.

${ }^{187}$ Cicero, Pro Caelio 49.

${ }^{188}$ Ibíd., 32,57.

${ }^{189}$ Ibíd., 62.

${ }^{190}$ Cicero, Pro Caelio 62,69.

${ }^{191}$ Plutarchus, Cicero 29.

${ }^{192}$ QUintilianUs, Institutio oratoria 8,6,53.

${ }^{193}$ Cicero, Pro Caelio 1.

${ }^{194}$ GefFCKEn, Kathrine, cit. (n. 132), p. 38.
} 
BARWICK, Karl, Das rednerische Bildungsideal Ciceros (Berlin, Akademie-Verlag, 1963).

Benner, Herbert, Die Politik des P. Clodius Pulcher (Stuttgart, Steiner, 1987).

Classen, Johannes, Ciceros Rede für Caelius, en Temporini, Hildegard - Haase, Wolfgang (editores.), Aufstieg und Niedergang der römischen Welt (Berlin - New York, De Gruyter, 1973), I,3.

Cooper, Lane, An Aristotelian Theory of Comedy (New York, Hancourt, 1922).

Costa, Emilio, Cicerone giureconsulto (Bologna, Nicola Zanichelli, 1927).

Dorey, A. T., Cicero, Clodia, and the pro Caelio, en Greece and Rome, 5 (Cambridge, 1958).

Epstein, David F., Cicero's Testimony at the Bona Dea Trial, en Classical Philology, 80 (Chicago, 1986).

FRYE, Northorp, Anatomy of Chriticism (New York, Schocken, 1969).

GefFCKEn, Kathrine, Comedy in the pro Caelio (Leiden, Brill, 1973).

Graillot, Henri, Le culte de Cybèle, Mère des Dieux à Rome et dans l Empire romain (Paris, Pontemoing, 1912).

HeInze, Richard, Ciceros Rede pro Caelio, en Hermes. Zeitschrift für klassische Philologie, 60 (Berlin, 1925).

KUNKEL, Wolfgang, Untersuchungen zur Entwicklung des römischen Kriminalverfahrens in vorsullanischer Zeit (München, Beck, 1962).

LATTE, Kurt, Römische Religionsgeschichte (München, Beck, 1967).

Mommsen, Theodor, Römisches Strafrecht (Leipzig, Duncker\&Humbolt, 1899).

Moreau, Philippe, Clodiana Religio. Un procès politique en 61 av. J-C. (Paris, Les Belles Lettres, 1982).

Münzer, Friedrich, Aus dem Leben des M. Caelius Rufus, en Hermes. Zeitschrift für klassische Philologie, 44 (Berlin, 1909).

MünZER, Friedrich, Römische Adelsparteien und Adelsfamilien (Stuttgart, Metzler, 1920).

SAINT Denis, Eugène de, Le plus sprituel des discours cicéroniens: le Pro Caelio, en Saint Denis, Eugène de, Essais sur le rire et le sourire des Latins (Paris, Les Belles Lettres, 1965).

Salzman, Michele R., Cicero, the Megalenses and the Defense of Caelius, en American Journal of Philology, 103 (Baltimore, 1982).

SEGAL, Erich, Roman Laughter (Cambridge, Cambridge University Press, 1968).

Spielvogel, Jörg, Clodius P. Pulcher, eine politische Ausnahmeerscheinung der späten Republik?, en Hermes. Zeitschrift für klassische Philologie, 125. (Stuttgart, 1997).

STroH, Wilfried, Taxis und Taktik. Die advokatische Dispositionskunst in Ciceros Gerichtsreden (Stuttgart, Teubner, 1975).

Tatum, W. Jeffrey, Cicero and the Bona Dea Scandal, en Classical Philology, 85 (Chicago, 1990).

TrencsényI-Waldapfel, Imre, Cicero (Budapest, Gondolat, 1959).

Uttschenko, Sergej Lvovič, Cicero (Berlin, Deutscher Verlag der Wissenschaften, 1978).

WILL, Wolfgang, Der römische Mob (Darmstadt, Wissenschaftliche Buchgesellschaft, 1991). 